endeavoured to illustrate the influence of a diseased father apon his offspring, the mother remaining healthy. In some instances I am about to bring forward, I shall show that there are certain circumstances under which the mother may be the source of the disease, the father remining healthy, never having been diseased.

The mother may be the source of disease to her foetus, or infant, in four ways :

1. She may be diseased before conception.

2. She may become diseased after she has conceived.

3. She may disease her infant in its passage through the vagina or external parts, a sonrce of infection formerly supposed to be very common, but in reality very rare.

4. She may disease it after birth. The first mode of infection has been commonly called hereditary, the second congenital, and the two last acquired. It is not always easy, or even possible, to point out the separate or distinct influence of each parent in the production of a diseased child, but the cases I have adduced in reference to the father I think must be convincing, and I am about to detail two others, which, on the part of the mother, will in all probability be found equally so.

CASE 7.-A. C-, a very healthy woman, married to a healthy man, a tradesman, gave birth to four healthy children, all now living, during the first seven years of her marriage. Whilst nursing her fifth child, she had occasion to send for a woman to draw her breasts. Soon after this, she perceived ulcers about the nipples, to these succeeded copper-coloured blotches, spread pretty extensively over the body, and a sorethroat; the child she was nursing dwindled away and died. The next three children were born dead; two others soon after birth had eruptions on the skin, and wasted away and died. The disease on the part of the mother was not suspested, nor Was she, during the time I have mentioned, treated. Her husband during all this time remained in the best health. After the death of the fifth child, she consulted me about ulcers on the legs, which were due to the detachment of the crusts covering some of the blotches I have just mentioned. I examined her carefully. She was then suffering from a distinctly and well-marked syphilitic lepra, the symptoms of which disappeared under a treatment by mercurial vapour. In this case, the separate influence of the mother is well shown. We observe a healthy father, a healtby mother, four healthy children; then the breast diseased by a suck-pap, followed by an eruption of marked character, a sore-throat, the child then sucking, wasting, and dying, and subsequently three children born dead, and two dying of wasting of the body, preceded by eruptions on the skin, all this time the father having no symptom of disease. A similar series of phenomena might follow if a diseased child were placed with a healthy wetnurse. If the nurse became again pregnant, she might probably give birth to a diseased child. I quote a care from M. Cazenave to illustrate this.

CAse 8.-A wet-nurse, previously healthy, received an infant to suckle, which, fifteen days after birth, had blotches on the vulva and ulcers on the mouth. It died at the age of three months. Soon after the death of this infant, the nurse perceived tubercles on the genitals. Six months after, she was delivered of a daughter, which, at its birth, appeared healthy, but soon afterwards had condylomata of the vulva and perinæum, and an eruption on the thighs."

The mode of infection, and the infiuence of the mother, is precisely the same in this case as in the last, although it is not so remarkable, neither is its history as defined and clear. I shall adduce one other instance before leaving this point of $\mathrm{my}$ subject.

CASF 9.-A healthy man, married a very healthy woman. I knew them both. At the usual period, and at her full time, she was delivered of a remarkably fine boy. All went on well for three weeks, when the breasts became troublesome, and a suck-pap of confessedly indifferent character was employed. Soon after this an nlcer formed near the nipple, which was difficult to heal, but at length got well under the use of blackwash. Soon after this the patient became covered with an eruption, which $I$ saw; it was a well-marked syphilitic roseola. The infant had a similar eruption; and then a large sore near the anus. The mother also had a very sore mouth, and vlcers on the tongue. The symptoms disappeared under treatment. The patient became again preguant. She aborted, or was rather prematurely delivered of a dead child, in the seventh month of pregnancy. She became pregnant a second time, and was again prematurely delivered in the seventh month of a dead infant. During the whole of this period the

* Cazenare. Rerue Médicale de Paris, 1852, p. 100 father remains perfectly healthy, and has never suffered from syphilis.

I could cite many more cases of a similar character from my own practice, and those of others; but those which have been already given are sufficient to show the occasional separate and single intluence of the mother in the procreation of syphilitie offspring. What length of time the taint may remain in the mother, if not properly treated, it is difficult to say. I am of opinion for long periods, as Case 7 shows. I have very little faith in syphilis, in such instances, wearing itself out.

It will be observed, that the influence of the mother in the production or communication of disease to her offspring is different in the cases I have just recorded. In the first instance, she is healthy, and gives birth to a bealthy child; she then becomes diseased, and communicates such disease to the sucking infant. This is what I have described as acquired syphilis; and the prospect of cure by judicious treatment is much greater than in the second case, where the mother, remaining nncured, again conceives and gives birth to a diseased child. Here the disease becomes hereditary. The parent diseased before conception gives birth to a diseased child, which is then formed and developed in the womb of a tainted mother.

In the first case the infant may generally be cured; in the second, if the child is born alive, the prospect of cure is uncertain and improbable, hence $M$. Lagneau has said, "Infants conceived and developed in the womb of a female suffering from constitutional syphilis seldom live beyond the period of the first dentition; if they survive this period their health is generally delicate and precarious, in spite of the most rational treatment that can be adopted." ("Syphilis de la Femme Enciente," p. 283. Paris, 1817.)

It will be observed that, in the cases I have hitherto mentioned the infant is diseased in three different ways; and I think a different prognosis attaches to each mode of origin. In the first case, the father impregnates the ovule with diseased semen, constitutional syphilis in him being either latent or manifest : but the product of the ovule, the foetus, is nourished and developed in the womb of a healthy female. In such case, if a diseased child be born, a reasonable hope of cure may be entertained, and such hope is commonly fulfilled.

In the second case, where the mother and father are both healchy, and the former becomes diseased after birth, and communicates such disease to her offspring in the way already described, the infant may generally be cured.

In the third case, where the infant is conceived and developed in the womb of a mother diseased before conception, the prognosis is, as I have already stated, most unfavourable.

\section{OSSIFICATION OF THE AORTIC VALVES, WTTH ANEURISMAL DILATATION OF THE AORTA.}

\section{BY JABEZ HOGG, EsQ., M.R.C.S.}

Mr. Alfred N- aged twenty-six, a commercial traveller, whilst on his journey in the country, in January 1854, was greatly alarmed by a violent fit of coughing, which ended in spitting of blood. After some days' medical treatment he was sufficiently recovered to attempt a return home. The exertion reproduced the hæmoptysis. Upon applying the stethoscope, a tolerably lond valvular unurmur over the upper part of the sternum, with a distinct bruit, was detected, which led me to believe in the existence of aneurism with hrmoptysis from pulmonary congestion. In three weeks he was convalescent. No further hæmorrhage gave me alarm, but his progress to bealth was slow, and the bruit might still be heard, although it was not so audible. He was, however, able to take out-door exercise in a very moderate degree until June, when he imprudently took a long walk and rode back on the top of an omnibus; this procedure, soon after his arrival at home, reproduced the cough and the hæmoptysis. The bruit increased, and the action of the heart was laboured and loud; a slight pulsation, with a vibratory thrill, was imparted to my fingers when pressure was made near the first and second rib to the right of the sternum. The patient now complained that this peculiar pulsation impeded respiration. Lung disease on the left side was apparent; nevertheless he was convalescent in about four weeks, but, continuing weak, I requested Dr. Hyde 
Salter to examine him, who confirmed my opinion as to the existence of aneurism of the aorta with pulmonary lesion.

Towards autumn he had apparently recovered, and could take his daily walk with comfort. He now thought of turning his attention once more to business, but in February, 1855, was again alarmed by the return of hæmoptysis. From this attack he soon rallied, and enjoyed tolerable health throughout the summer. In November the spitting of blood once more returned, which the usual remedies arrested; the cough left him, and he experienced no further attack until the end of January 1857.

In consequence of his removal to Hackney, he next came under the care of $\mathrm{Mr}$. Hacon, and this gentleman kindly furnished me with the following particulars of his last illness :-

" Early in February I found him suffering from hæmoptysis. The quantity of blood lost was small, not more than half an ounce at a time, and I do not think the whole quantity raised amounted to two ounces during the illness, lasting about a month. He was at this time emaciated and weak, but had hardly any cough. He complained of a sore spot on the upper part of the left side of the chest, from which he said he was sure the blood came. This pretty nearly corresponded with the situation of the cavity found in the lung after death. There was no perceptible dulness about this part of the chest, nor any expectoration beyond a slight quantity of mucus tinged with blood, which very soon ceased. At this time there was much palpitation of the heart, which could be felt over all the anterior parts of the chest. An abnormal pulsation was also very perceptible over the upper portion of the sternum. A loud 'bruit de soufflet' accompanied the heart's action, and masked the second sound of the heart; this bruit was also heard over the upper part of the sternum; and when the action of the heart somewhat subsided, the pulse was often intermittent and feeble, although during the hæmoptysis the intermittence had not been remarked.

Although he had some two or three attacks of hæmoptysis during the summer, he was well enough to walk short distances without inconvenienee, and for many months prior to the last attack he had no hromoptysis. In January of this year he had, however, a fresh attack, but the amount of blood lost was trifling, and entirely ceased after a few days' treatment, and in the early part of February he was much better, although he did not leave his room. In the middle of the month his breath ing became affected, and he was unable to lie down. This dif ficulty rapidly increased, and for several weeks prior to his death he could only breathe by leaning forward, and resting his head on his hands, and even in this position he was, on several occasions, threatened with asphyxia; on one especially, when his face had become livid, his extremities cold, and his trachea filled partially with mucus, so that immediate death seemed inevitable, a slight alteration of his position caused him to rally, and he lived nearly a fortnight after. During the whole of this last illness he was able to take but little food, and he sank from exhaustion, the dyspnœa not being quite so distressing a day or two prior to his death, which occurred on the 25th of March."

Post-mortem examination thirty hour's after death. - The body was much emaciated, and the extremities cedematous. The heart was considerably raised, the pericardium being distended with several ounces of fluid; there was evident enlargement of the heart: it contained a good deal of dark blood and fibrinous clots. On the left side there was evidence of recent pleurisy, with serous effusion; the left lung was large and gorged with dark blood, and there was a small cavity as well as pulmonary tubercles on several portions of it. In the right lung, which was smaller than the left, there was miliary tubercle, but not to the same extent as in the right. The mucous membrane of the trachea was of a dark mahogany colour.

The diseased appearances of the heart were,-lst, enlargement; 2nd, ossification of the aortic valves; 3rd, aneurismal dilatation of the aorta

The enlargement of the heart was both by hypertrophy and dilatation; all the cavities were enlarged, and the walls of the left ventricle greatly thickened. This was doubtless caused by the aortic constriction. The heart weighed, after the careful removal of all clots and blood, seventeen ounces. The ossification of the aortic valves was such as entirely to destroy their normal anatomy, and to convert the orifice into a narrow fissure. The valves were so contracted as almost to be effaced, and what was left of them was puckered, thickened, leathery, and almost cartilaginous in texture. The calcareous matter was deposited in large masses of dense fibrous tissue, having the consistence of cartilage; most of these were placed along the attached margin of the valves, converting it into a bony ring, but one of considerable size was quite free of the valves, fairly within the aortn, and projecting into one of the sinuses of Valsalva. Such a state of disease, while it admitted regurgitation, must chiefly have produced obstruction, and that of an extreme character.

The aneurismal dilatation involved the ascending aorta, and about two-thirds of the arch, from the valvular orifice to just beyond the origin of the left subclavian artery, where it rather suddenly ceased. It was of a very equable and cylindrical character, widest at the junction of the ascending sixth, with the arched portion, and there two inches in diameter. The dilated portion was also elongated, and measured from the root of the vessel to the origin of the left subclavian artery, four inches. There was nothing peculiar in the feel of the vessel, it appeared to be firm, elastic, smooth, natural, and of even and sufficient thickness, except the anterior surface of the horizontal portion of the arch, which was very thin. On cutting out a circular piece from behind, and looking to the inner surface of the vessel, it was found smooth, and in every way natural. The aneurism had contracted no undue adhesions with surrounding parts. From its situation and direction it must have pressed principally upon the right pulmonary artery and the left bronchus, as they both lie beneath the arch. The right pulmonary artery was found in this situation, and so contracted as only to admit a pen-handle; it was contracted to a third of its natural diameter; a very small supply of blood must have been delivered to the right lung. The left pulmonary artery entirely escaped pressure, and must have been the vehicle of an unusually large column of blood, and thus an undue supply must have been thrown upon the left lung, whife the pressure upon the left bronchus shnt off the air, and kept the respiration of the lung in permanent arrears. This will account for the extreme congestion of the left lung, and for its being so much greater than the right. Some pressure must have also been exercised upon the cavæ, especially the superior. I should think that the urgent dyspnoen and death resulted from the pressure upon the roots of the lungs, and the consequent derangement of the supply of air and blood to them. It is difficult to account for the aneurism, for except at the point I have mentioned, (just below the origins of the arteries from the arch,) the walls of the aorta were perfectly healthy, no ossification, no atheroma, no divergence in any respect from the normal appearance, thickness, or strength. Moreover, the valvular disease was not such as to produce distention, or to imply that the walls of the artery were subjected to any undue stress, but the reverse; such as would diminish the stress to which it would be subjected in health. For, on the one hand, the contraction of the aortic orifice would prevent the arterial volume of blood from being sent into the aorta at each systole of the heart, and the imperfect closure of that orifice would allow an immediate reflux and relief of the aorta the moment the ventricular contraction ceased.

These circumstances, together with the comparative youth of the patient, certainly makes the case peculiar. Although young, he had, however, lived somewhat fast; had drunk a good deal at one time, and "knocked about the country, and undergone violent and Jaborious exertion." The case is also. somewhat confirmatory of Trousseau's opinion, that hæmoptysis is more frequently associated with disease of the heart than with pulmonary tubcrcle. The pulmonary tubercle was, in this case, subsequent to the disease of the heart, the patient having been examined four years prior to his death for lung. disease, and none was then detected. It is somewhat remark. able, also, that the coats of the artery should have been quite free from all atheromatous deposit.

Gower-street, May, 1858 .

ON $\triangle$ CASE OF

BRONZED-SKIN DISEASE OF THE SUPRARENAL CAPSULES.

By R. RICHARDSON, EsQ., L.F.P.S. Glasgow.

As there are few cases of recovery from this formidable disease on record, I am induced to forward the following. I shall here simply state facts, without entering at great length into all the details. In so doing $I$ shall take the reports from $m y$ note-book monthly, as the period of treatment extends to about twelve months. 